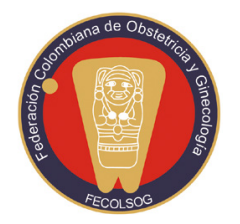

\title{
LOS DERECHOS SEXUALES Y REPRODUCTIVOS DE LA MUJER EN LA AGENDA DE LOS OBSTETRAS Y GINECÓLOGOS DE LA REGIÓN LATINOAMERICANA Y DEL CARIBE
}

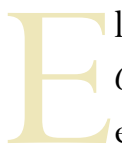
1 actual número de la Revista Colombiana de Obstetricia y Ginecología (RCOG) presenta varios estudios que ponen sobre el tapete la realidad de los derechos sexuales y reproductivos de la mujer en la región, los cuales están en estrecha relación con otros derechos humanos como los derechos a la vida, a la salud, a la educación, a la privacidad y a la no discriminación.

Según el Comité para la Eliminación de la Discriminación Contra la Mujer (CEDAW, por sus siglas en inglés) (1), la salvaguarda de estos derechos es responsabilidad de los Estados, en tanto estos deben garantizar las condiciones para el mayor bienestar físico y emocional de la mujer en los diferentes momentos de la vida, como también la provisión suficiente de servicios de salud sexual y reproductiva, un adecuado acceso a ellos desde el punto de vista físico y económico, y velar por que estos servicios sean de buena calidad.

El quebrantamiento de los derechos sexuales y reproductivos de nuestras mujeres se evidencia en los diferentes estudios publicados en este número de la RCOG. En el estudio realizado por Ávila-Quintana et al. se informa que las características socioambientales de los barrios o vecindarios afectan la actividad física en el embarazo. Esta actividad física es deseable para evitar el incremento exagerado de peso durante el mismo, reducir el dolor postural en la gestación y posibles alteraciones del afecto. Ellos describen una asociación importante entre la percepción de inseguridad y un mal estado de las aceras -más frecuente en los vecindarios de la población pobre-, con una actividad física limitada. Por otra parte, el documento de Gómez-Dávila presenta de manera clara cómo, a pesar de haber leyes que protegen a la mujer que decide abortar, estas en la práctica se aplican de manera diferencial en cuanto a la posibilidad de acceder a un aborto seguro; señalan además, que solo a través de la educación se dará a las mujeres la oportunidad de tomar decisiones con la suficiente libertad. Para el caso del aborto hay restricciones a los derechos de las mujeres cuando se presenta discriminación por parte de los trabajadores de la salud, que pueden llevar a la negación del servicio por consideraciones de tipo religioso o limitaciones de acceso derivadas de trámites administrativos, autorizaciones de servicios por parte de las aseguradoras privadas encargadas de la administración de los planes de cobertura en los países con sistemas de aseguramiento privado como Colombia. Estas desigualdades afectan de manera importante a las mujeres de menores ingresos económicos.

Por otra parte, los valores de una sociedad patriarcal como la presente en América Latina y el Caribe afectan el adecuado ejercicio de una sexualidad plena y libre por parte de las mujeres en la región como queda evidenciado en el estudio de Espitia-De la Hoz, quien reporta una importante prevalencia de disfunción sexual en una muestra de mujeres en varias ciudades de Colombia. Este estudio también presenta una importante prevalencia de vida de violencia sexual en una sociedad en la que predominan los derechos de los hombres y la justicia es aplicada predominan- 
temente por estos. Los hallazgos de violencia sexual, baja educación y bajos ingresos también están presentes en el artículo de Leal-Díaz et al. que estudia la frecuencia de antecedentes de comportamientos sexuales de riesgo en mujeres privadas de la libertad en Chile. Por último, en el estudio de Cáceres-Manrique sobre los factores que condicionan un inicio tardío del control prenatal, sobresalen la pobreza y el bajo nivel educativo, y la temprana edad de las gestantes, estrechamente relacionados entre sí.

Las anteriores violaciones de los derechos a la vida, la salud, la educación y la no discriminación, así como de los derechos sexuales y reproductivos, compartidas por la gran mayoría de los países de la región, no son solo responsabilidad de nuestros gobiernos, que no garantizan la salud de las mujeres, en especial de las más pobres y vulnerables, y que no consideran la educación su como la mejor vía para salir del subdesarrollo y la pobreza, y de garantizar que las personas tengan la libertad real de tomar las mejores decisiones de vida. Son también responsabilidad de la sociedad en general, que debe dar mayor valor a los derechos de la mujer, para que haya un mayor respeto por su vida, para que pueda salir del círculo de pobreza y vulnerabilidad
En cuanto a nuestra responsabilidad, los ginecólogos y obstetras de la región, como agrupación científica, debemos luchar como aliados de nuestras mujeres para que se respeten sus derechos sexuales y reproductivos, aportando evidencia a fin de que se definan políticas de Estado que actúen sobre los determinantes sociales que perpetúan las inequidades en salud y, por último, como médicos clínicos, mediante la adecuada capacitación para poder responder a las necesidades de la mujer para que tengan una vida sexual sana y satisfactoria, que favorezca una buena salud reproductiva, de manera que puedan definir de forma autónoma cuántos hijos y cuándo los quieren tener, para el mayor bienestar de sus familias.

\section{Hernando Gaitán-Duarte, MD, MSc}

Editor

\section{REFERENCIA}

1. United Nations Human Rights. Office of the High Commissioner. Sexual and Reproductive Health and Rights. 2015 [visitado 2018 mar 20]. Recuperado de http://www.ohchr.org/EN/Issues/Women/WRGS/ Pages/HealthRights.aspx. 